\title{
SANTO ANTÔNIO DO ARACAJU: etnografia e narrativas sobre um lugar
}

\author{
SANTO ANTÔNIO DO ARACAJU: \\ ethnography and narratives about a place
}

Ulisses Neves Rafael

\begin{abstract}
Resumo
O bairro de Santo Antônio de Aracaju e as celebrações anuais em homenagem ao seu padroeiro, têm sido objeto, ao longo do tempo, de estimulantes considerações por parte da intelectualidade sergipana. Nosso objeto de interesse aqui se pauta nas imagens localizadas na literatura, principalmente, as quais levam em conta, sobretudo, aspectos afetivos que concorrem de forma decisiva para a construção de uma imagem do local pautada nas ideias de tradição, antiguidade, isolamento e singularidade. Tais representações contrastam fortemente com as visões de planejamento, progresso e modernidade associadas à capital como um todo.
\end{abstract}

Palavras-chave: Festas. Santo Antônio. Intelectualidade. Representações.

\begin{abstract}
The neighbourhood of Santo Antonio in Aracaju and the annual celebrations in homage to this patron saint, have been object, over time, of stimulating considerations on the part of the sergipana intellectuality. Our purpose here turns to the images elaborated through literature, mainly, which take into account, above all, affective aspects that compete decisively for the construction of an image of the place based on the ideas of tradition, memory and identity. Such representations contrast sharply with the visions of planning, progress, and modernity associated with the capital as a whole.
\end{abstract}

Keywords: Religious festivities. Santo Antonio. Intellectuality. Representations.

\section{Introito}

A trezena de Santo Antônio do Aracaju, apresenta-se como uma das mais emblemáticas expressões do calendário religioso de Sergipe. A festa em sua homenagem tem sido objeto de análises estimulantes, dentro e fora do Brasil ${ }^{1}$, embora, pelo menos entre nós, quase sempre o enfoque recaia sobre o aspecto histórico da devoção popular, trazida para cá desde o início da colonização portuguesa. As versões locais desses estudos são pesquisas complementares que

\footnotetext{
* Professor Associado IV do Departamento de Ciências Sociais e do Programa de Pós-Graduação em Antropologia da Universidade Federal de Sergipe. Doutor em Sociologia e Antropologia pela Universidade Federal do Rio de Janeiro (2004), realizou Estágio de Pós-Doutorado no Núcleo de Estudos sobre Cidades e Culturas Urbanas (NECCURB) do Centro de Estudos Sociais da Universidade de Coimbra. Atualmente coordena o Grupo de Pesquisa Cultura, Cotidiano e Sociabilidades na Contemporaneidade, no qual desenvolve pesquisa sobre Festas, Patrimônio, Cultura Urbana, Boemia Literária e Intolerância Religiosa no Brasil. E-mail: ulisses38@gmail.com

1 Para uma compreensão do perfil geral das festas de santos em Portugal, dentro das quais se inserem as homenagens a Santo Antonio, ver Cordeiro \& Costa (1999) e Frúgoli Junior (2014), embora a festa abordada nessas obras guarde pouca relação com os nossos festejos juninos, conforme tentamos demonstrar no artigo Festas populares sob perspectiva comparativa: Brasil e Portugal (RAFAEL, 2013). Ver também Sandroni e Salles (2013), Amaral (1998) e Del Priore (2000).
} 
levam em conta, principalmente a história do bairro e da construção da capela desde tempos imemoriais, entre outros aspectos valorativos que concorrem para o fortalecimento da imagem de uma comunidade que imprime uma marca identitária forte à cidade, cujo processo de construção é o tema deste trabalho².

Assim sendo, e para escapar do lugar comum que nas pesquisas do gênero se faz notar, temos buscado elementos que permitam uma compreensão da festa de Santo Antônio para além da sua procedência e da sua estrutura convencional. Além do valor intrínseco das trezenas em si, enquanto rito emblemático, através do qual a comunidade local, e a cidade como um todo, parece se afirmar em termos de uma unidade identitária, sugerimos levar em conta o estoque simbólico subjacente e que se revela mais sutilmente nas representações escritas encontradas em fontes historiográficas e literárias, ${ }^{3}$. Portanto, propomos colocarmo-nos para além dos aspectos formais e materiais da festa e que dizem respeito a fatores como a organização do calendário, distribuição das tarefas, patrocínio, comércio envolvido, perfil socioestrutural dos participantes, etc. Interessa-nos uma abordagem acerca dos sistemas de valores e representações que concorrem para a construção da ideia de uma suposta unidade local, bem como para a imagem de festa mais tradicional na cidade ${ }^{4}$.

O nosso corpus informativo aqui é composto por aquilo que estamos denominando de elite intelectual sergipana, ou pelo menos de parte dessa categoria composta por escritores, poetas, memorialistas e acadêmicos, cujos nomes costumam constar nas enciclopédias, dicionários e efemérides locais. A reunião desses autores, cujas obras foram produzidas em períodos distintos entre si, faz-se tomando como critério a menção à formação urbanística de Aracaju e, particularmente, ao bairro de Santo Antônio.

No rol dos escritores, o nome de Mário Cabral (1914-2009) aparece como um dos mais importantes ícones da literatura sergipana. Escreveu várias obras tendo a cidade de Aracaju como seu pano de fundo, entre as quais destaca-se "Roteiro de Aracaju", que aqui utilizamos mais amiúde em nossa investigação. Outro escritor de renome equivale, é Amando Fontes (18991967) que, embora nascido em Santos (SP), viveu em Aracaju desde os cinco meses de idade até a Revolução de 1930. Escritor bissexto, publicou apenas dois romances, Os corumbás (1933) e Rua do Siriri (1937), publicados quando ele já se encontrava residindo no Rio de Janeiro, embora as tramas se desenvolvessem completamente em Aracaju. Utilizaremos para efeito de

2 A utilização do termo comunidade que aqui fazemos inspira-se na discussão levantada por Antonio Firmino da Costa (2008), para se referir às configurações da estrutura social marcada por um alto grau de preservação dos modos de vida considerados tradicionais, nomeadamente as unidades locais em que se apresentam mais claramente as representações desse espaço como "lugar de experiências partilhadas e de sentimentos de pertença" (2008, p. 47). Estamos cientes dos riscos de simplificação que a categoria reserva, mas se a utilizamos aqui é mais como um tipo ideal (Cf. WEBER, 1994).

3 O conceito de representação que aqui utilizamos, ampara-se, grosso modo, na contribuição de Roger Chartier (1991), para quem o termo se refere às inscrições (ideias e discursos) produzidas pelos indivíduos, dotadas de eficácia, e que constituem instrumento essencial para a análise e compreensão da realidade cultural.

4 Tal recorte se inspira nas contribuições de Graças Índias Cordeiro e Antonio Firmino Costa (1999) e Graças Índias Cordeiro (1997). 
análise aqui a saga da família de imigrantes sergipanos que na capital do estado vai se instalar no bairro de Santo Antônio, contida no primeiro romance, o qual alcançou boa receptividade nos circuitos literários cariocas da época.

Outro segmento composto por essas elites ilustradas é formado pelos acadêmicos que, nas suas respectivas áreas, basicamente a história e a geografia, são detentores dos saberes a respeito do passado e do território. Na primeira categoria podemos situar José Calazans Brandão da Silva (1915-2001), cuja carreira culminou com a livre-docência de História do Brasil na Faculdade de Filosofia da Universidade Federal da Bahia, onde lecionou também as disciplinas de História Moderna e Contemporânea. Entre os inúmeros artigos por ele publicados sobre História e Folclore, utilizaremos, para efeito desta análise, principalmente, as ideias contidas no livro Temas da Província, e que em 2013 seria republicado com o título que aparece nas referências aqui citadas: Aracaju e outros temas sergipanos.

Por outro lado, destaca-se o nome do engenheiro Fernando Porto (1911-2005), a principal referência nos estudos geográficos locais, com a obra A Cidade do Aracaju 1845-1965. Ensaios de evolução urbana (1946) é uma das principais defesas dessa visão naturista que seria reproduzida por parte da intelectualidade sergipana e que aponta o processo de desenvolvimento da nova capital como "uma vitória da Geografia", em alusão à topografia da região central da cidade. Junto com José Calazans e Mário Cabral, Fernando Porto organizou a Revista de Aracaju, que a partir dos anos 1940 tornou-se, ao lado da Revista do Instituto Histórico e Geográfico de Sergipe, a principal publicação no estado.

Por fim, temos o grupo formado pelos memorialistas, dentre os quais destaca-se o nome de Murilo Melins (2007), em cuja obra, Aracaju Romântica que vi e vivi. Anos 40 e 50, vamos encontrar os relatos mais robustos sobre o bairro de Santo Antônio e as festas ali realizadas. Marluce Nascimento Menezes, por sua vez, escreve o mais pungente relato do local, como informante de primeira mão, já que sua infância e adolescência foram vividas no bairro.

No geral, todos esses autores, não obstante a diferença entre os períodos mais fecundos de sua produção e sua posição no cenário intelectual, integram a mesma função na produção de sentidos acerca da cidade de Aracaju no geral, e do bairro do Santo Antônio em particular, razão pela qual são aqui transformados em sujeitos desta análise. Tal produção intelectual se apresenta também como parâmetro comparativo com a produção etnográfica própria que mais adiante apresento, sobre a festa de Santo Antônio em contexto mais contemporâneo, para estabelecer conexões acerca das retóricas convergentes e discrepantes sobre um mesmo local.

\section{Aracaju: uma cidade e a natureza}

Aracaju é uma capital cujas características topográficas, se não justificam, pelo menos 
explicam uma certa "insularidade" presente desde a sua fundação até a expansão e ocupação de áreas novas em períodos mais recentes ${ }^{5}$.

A imagem aquática, principalmente, foi explorada ad nauseam por inúmeros estudiosos do tema para representar a cidade em seus primórdios, os quais destacam também a complexidade de outros aspectos materiais inerentes ao contexto local; fatores de impedimento do desenvolvimento acelerado de uma capital de fundação recente, até para os padrões nacionais e, por que não dizer, continentais, cuja origem remonta à "aurora do século XVI”.

A "sultana das águas" recebeu a atenção redobrada de historiadores, cronistas e memorialistas, que optaram por destacar, pelo menos com relação à primeira fase de sua evolução, os aspectos naturais do lugar dos cajueiros ${ }^{6}$. As péssimas condições sanitárias eram motivo das constantes queixas da população, atestadas, inclusive, por viajantes como Avé-Lallemant, que em sua passagem por Aracaju, em 1859, registra "a falta de boa água potável", motivo das febres intermitentes das quais ele próprio padeceu durante os dias que permaneceu na capital sergipana.Na justificativa para a transferência da capital, embora atenue os aspectos naturais em favor de fatores comerciais, tais como a proximidade de área propícia à construção de um porto para escoamento da produção do açúcar, fator também associado às condições geográficas e topográficas específicas, Fernando Porto (1991) não deixa de mencionar as "praias desabitadas", os estuários largos, as águas estagnadas, os mangues, os pântanos, o "deserto de lama”, entre outros, motivos do isolamento material e simbólico de que falamos há pouco: "Bem pesadas as coisas, Aracaju nasceu numa ilha. (...). Uma terra que qualquer aguaceirozinho enquadrava na mais elementar definição de ilha” (PORTO, 1991, p. 35).

E, por fim, entre os principais expoentes de uma interpretação de Aracaju, que aqui estou denominando de naturista e, talvez, dentre eles o que mais romantizou a relação da cidade com o meio, Mario Cabral (1955) deixará sua marca entre os estudiosos contemporâneos, embora nem sempre pelas imagens idílicas com que abre sua obra, Roteiro de Aracaju:

A Cidade de Aracaju, (...) nasceu assim: feia, pobre, impaludada, perseguida por muitos, ajudada por alguns. Ao nascer não contemplou outra coisa que não fosse mangues, lagoas, pântanos e alagadiços. Engatinhou sobre um charco imenso, onde, nas noites longas e tristes, a saparia coaxava em um coro potente e numeroso (CABRAL, 1955, p. 37).

\footnotetext{
5 A inspiração para a ideia de insularidade aqui utilizada foi buscada na literatura de ficção, o que fazemos cientes da distância que Aracaju guarda dos contextos marítimos propriamente reclusos com relação a um suposto continente, embora seja de isolamento físico, exatamente, de que estamos tratando aqui, além, também, do sentido antropológico que adota a ideia de insulamento cultural, obtido a despeito das condições ambientais (Cf. Veiga, 1998) e sobre o insulamento cultural, Cf. Benedict (2015).

6 Relatório apresentado à Assembleia Provincial de Sergipe, no dia 5 de março de 1860 pelo presidente, Manuel da Cunha Galvão (1860).
} 
Evidentemente esse tipo de discurso não se reduz aos poucos casos aqui mencionados. Ele é parte de uma construção que se fez mais presente, principalmente, por ocasião da comemoração do centenário da fundação da cidade, ocorrido em 1955, embora a tendência tenha se estendido por um largo tempo além daquele marco comemorativo, e entre áreas variadas do conhecimento, que vão da história à geografia, passando pela sociologia, arquitetura, entre outras ${ }^{7}$.

Assim, os testemunhos e registros acerca das origens da recém-criada capital, caracterizam-se pelo destaque à paisagem natural, como suas elevações de terreno constituídos por materiais finos, as famosas dunas, em cujos desnivelamentos ou cavas abriam-se espaços para a formação de pequenos charcos e lagoas; além dos manguezais e apicuns frequentes por toda extensão das margens paludosas do complexo fluvial que afeta toda a malha urbana, considerados, todos, fatores primordiais de retardamento do processo de ocupação demográfica e de comunicação entre as suas áreas constitutivas, concorrendo para a formação de verdadeiros enclaves no interior de uma capital que, a princípio, dispunha-se a ser integrativa, pelo menos nas primeiras décadas da formação ${ }^{8}$.

Às imagens soturnas da paisagem hostil da nova capital, composta por "praia inóspita", águas paradas e "febres intermitentes" 10 , vão sobrepondo-se, lenta e paulatinamente, a imagem do terreno conquistado através da "luta heroica" e da bravura do homem empreendedor, mais condizente com o estilo de vida propriamente urbanístico. No intuito de escapar às imagens de natureza indômita que marcaram sua origem, as representações sobre a cidade vão assumindo um tom mais colado ao progresso ${ }^{11}$.

Em meio ao embate entre essas visões envolvendo as duas capitais, a antiga e a nova, a colonial e a tropical, a barroca e a moderna, fadado a desaparecer à medida que São Cristóvão vai aos poucos perdendo seu protagonismo político, outro contraponto principal desponta para realçar a centralidade urbana de Aracaju, enquanto capital vitoriosa e moderna. Trata-se das representações que se interpõem na caracterização do remoto e aprazível Povoado de Santo Antônio, objeto de nossas considerações seguintes.

\footnotetext{
7 As representações acerca do aspecto insalubre e ameaçador do ambiente físico onde se fundou Aracaju têm sido uma constante também nos estudos realizados, principalmente, pelos geógrafos, cujas representações acerca da cidade aquática vamos encontrar em Loureiro (1983), Vilar (2002) e Araújo (2006).

8 Cf. Araújo (2006). op. cit.

9 Silva (1939).

10 Silva (2013).

11 As ideias aqui levantadas encontram respaldo nas assertiva de Waldefranklin Rolim dos Santos, para quem a cidade de Aracaju se insurge contra a natureza; ela se afirma na ideia de progresso e na supremacia da técnica sobre o ambiente. Nesse sentido, a arquitetura possui um papel preponderante para o pensamento que guia as práticas urbanas: ela se estabelece como "a imagem urbana" capaz de corrigir as “imperfeições naturais” (SANTOS, 2007, p. 78).
} 


\section{Povoado de Santo Antônio: a colina e o refúgio}

A primeira menção à capela de Santo Antônio encontra-se em documento da lavra do Padre José de Souza, vigário de Nossa Senhora do Socorro, freguesia à qual pertencia o povoado do Aracaju e onde se encontrava edificado o santuário, datado de 03 de março de 1757, e no qual o religioso "aborda o que viu e ouviu" em "trinta e cinco linhas estabelecidas em uma lauda incompleta", cujo teor "descreve rios importantes, limites e fronteiras, além de dados sobre população e povoamento", conforme informações prestadas por Santos (2008, p. 14).

O vazio informativo sobre o lugar deve-se, talvez, ao fato de o movimento povoador da região ter sido mais lento e demorado ali do que o verificado no Arraial de São Cristóvão, sede administrativa da Capitania criada em 1590. Note-se também o fato de se tratar de um reduto habitado por uma população pobre, formada majoritariamente por pescadores, incipiente por demais para ser objeto de preocupação por parte das autoridades políticas ou dos cronistas.

Independentemente das informações esparsas encontradas sobre a localidade, o fato é que o povoado, situado na Barra do rio Cotinguiba, depois denominado rio Sergipe, só aparecerá de modo mais efetivo nas narrativas históricas sergipanas após ser escolhido para sediar o centro administrativo da nova capital da província, em 1855. Embora, e apesar de, as condições ambientais mais favoráveis desfrutadas pelo promontório na ocasião, o Povoado foi relegado no desenho original do plano urbanístico idealizado para Aracaju, o qual manteve inalteradas, por um longo período, as características suburbanas do antigo povoamento situado no entorno da colina de Santo Antônio.

As notícias específicas acerca desse povoado continuam escassas nos anos imediatamente posteriores à transferência da capital. Tudo leva a crer, portanto, que a ocupação do bairro só deve ter se realizado de modo mais sistemático após a finalização da via de ligação, entre o arrabalde e "a parte mais rica da cidade" 12 .

Trata-se, portanto, da Estrada Nova, cuja construção começou ainda no governo do fundador da nova capital, o presidente Inácio Barbosa, mas que só foi concluída dois anos depois da transferência. Cumpre notar, portanto, as representações comuns, nesses e noutros tipos de registros, oficiais ou não, acerca do bucolismo do "aprazível outeiro" e do arrabalde pitoresco, cuja localização mais elevada se apresenta como alternativa habitacional à distante planície, com suas águas paradas e miasmáticas, representada através de imagens, pautadas, como já vimos, em sua natureza hostil e, aparentemente, indomável, não obstante as constantes intervenções que possibilitaram uma rápida alteração da sua feição aquática. As imagens construídas acerca do lugar remoto, antigo e acanhado, aplicadas ao Povoado de Santo Antônio, continuaram

12 Expressão utilizada por Amando Fontes no consagrado romance Os Corumbas (1999, p. 22). O termo "bairro" aparece pela primeira vez no lançamento da décima urbana dos distritos fiscais da capital, no exercício de 1877 a 1878, contanto com 37 imóveis (JORNAL DO ARACAJU, 1877). 
sendo veiculadas, mesmo e principalmente, quando o restante da capital aciona os símbolos da vanguarda e do desenvolvimento.

$\mathrm{Na}$ fase de implantação da nova cidade, também chamado "período da conquista da 'duna”, que abrange, segundo Porto (1991), os dez primeiros anos da nova capital, o Povoado do Santo Antônio concentrou parcela representativa da população que circulava em torno da escola primária e da capela onde, inclusive, teria sido celebrada a missa que consagrou a transferência ${ }^{13}$. Contudo, no período seguinte, compreendido pelas três primeiras décadas do século XX, e quando Aracaju se "afirma como sede do poder político-administrativo e econômico de Sergipe" (LOUREIRO, 1983), a expansão urbana verificada em várias direções da cidade não se reflete sobre o arrabalde. Inclusive as melhorias alcançadas pelo vizinho Bairro Chica Chaves, antigo Massaranduba, onde seriam fundadas as primeiras fábricas de tecido da capital - como a Sergipe Industrial, já em 1884, e a Confiança, em 1907 -, concorreram para a demarcação imaginária e definitiva que, entre as duas áreas contíguas, os respectivos moradores iriam estabelecer em função do próprio local de residência.

Frente a tal confronto tácito, o agora Bairro Industrial herdaria as impressões compatíveis com o perfil menos aquinhoado de sua população, cujas expressões culturais continuam, até hoje, sendo relegadas ao vulgar, ao ordinário e ao infortúnio, em favor das imagens de altivez e relevância com as quais se representam as práticas culturais, sobretudo religiosas, da Colina do Santo Antônio. Não que aí não se encontrassem também a "gente humilde", mas nem os arruamentos de que foram objeto o bairro, já em período mais avançado do desenvolvimento da capital, concorreram para apagar essas representações de lugar da tradição aplicadas a ele.

Amando Fontes deve ter sido o catalizador dessas impressões divergentes acerca dos dois bairros vizinho, já que no seu romance Os Corumbas, de 1933, reserva às ruas do recôndito Bairro Industrial, com seus apicuns e aterros, as práticas mais repulsivas, porquanto, frequentado pelos operários pobres, protagonistas da novela. A rua do Arame, a rua do Fogo e a "alameda ensombrada do Beco da Cerimônia"14, entre tantos outros logradouros situados naquele subúrbio, dão azo aos encontros espúrios, às reuniões boêmias à volta do violão e

$13 \mathrm{O}$ estudo sobre décimas urbanas, "imposto aplicado sobre todos os prédios contados pelos limites das cidades, vilas e lugares notáveis", realizado por Alexandre Ferreira Santos Neto, comprova, também, uma maior variedade populacional entre os anos de 1873 e 1880, período coberto por sua pesquisa, pelo menos em termos ocupacionais, composta por escravos proprietários, artistas e ganhadores: "Os cativos artistas eram operários em metais, madeiras, tecidos edificações, couros e peles, vestuários, tinturaria, chapéus e calçados. Escravo ganhador, quase sempre chamado de jornaleiro, eram prestadores de serviços, isto é, trabalhavam no comércio ambulante, no transporte de pessoas e mercadorias, tanto para os seus senhores como para terceiros. Trabalhadores livre e elite, reconhecida pelos títulos de Barão, coronel, tenente coronel, comendador. Possui acesso à casa própria e a moradias com valor locativo mais alto. A classe média englobava professores, militares de baixa patente, donos da agroindústria e comerciantes. Operários: chocadeiras, fogueteiros, barbeiros, funileiros, carpinteiros, marceneiros e pedreiros" (Cf. SANTOS NETO, 2005. p. 6-9).

14 Nomes antigos de ruas que ligam os bairros de Santo Antônio e Industrial, correspondentes na atualidade, respectivamente, às ruas Sargento Duque, que liga a avenida João Ribeiro ao Beco da Cerimônia que, por sua vez, tratava-se de uma passagem estreita entre a rua de São João e aquela avenida, e; por fim, à Japaratuba (Cf. BARRETO, 2002). 
às brigas contumazes, enquanto o Santo Antônio, "o ponto mais bonito de todo o Aracaju”, é referido como o espaço das grandes festas populares, sobretudo as religiosas que aconteciam na Praça da Matriz ${ }^{15}$.

Quanto ao Bairro de Santo Antônio, as esparsas notícias encontradas, e que vão substituindo gradativamente o vazio informativo sobre o local, começam a tomar corpo sobretudo com a chegada dos Franciscanos, sobre cuja irmandade recairão, a partir de 1935, os cuidados com a Paróquia, criada desde 1915, inclusive a construção da Matriz de Santo Antônio. A presença ali dessa congregação vai conferindo, paulatinamente, a proeminência simbólica que o bairro mantém, como espaço de tradição; mais uma imagem construída, desta feita, a partir da elite eclesiástica ${ }^{16}$.

No tópico seguinte, por meio da descrição etnográfica da Trezena de Santo Antônio, buscaremos destacar a ressonância entre os devotos dessas elaborações discursivas de procedência intelectual e também questionar quantas dessas representações não encontram substrato nas interpretações formuladas pelos fiéis diretamente envolvidos nas celebrações. Assim sendo, importa aqui o rastro dessa criatura que Ingold (2012) chama de tradição, capturando e costurando as memórias afetivas dos fiéis, protagonistas da festa, recuperadas para justificar a longevidade e a representatividade da festa no contexto local e municipal.

\section{A trezena de Santo Antônio em meio aos festejos juninos em Aracaju}

O período junino em Sergipe se apresenta como o mais concorrido dentre as festividades do estado, constituindo grande motivação de entretenimento e turismo, embora tenha perdido muito do seu aspecto religioso. Em Aracaju, é possível constatar a sua preeminência através da cobertura recebida por parte da mídia local, inclusive desde o mês de maio, período em que se realiza a abertura oficial da temporada, promovida pela prefeitura municipal, quase sempre regada a um café da manhã, dito "tipicamente" nordestino, oferecido à imprensa, mas também

15 Fontes, 1999. Vale frisar que, além das imagens associadas à pobreza e ao trabalho, as qualidades recreativas da localidade também receberam alguma atenção dos memorialistas locais, como na crônica "De bonde para o Bairro Industrial: um passeio nostálgico": Olhando aquela praia, vimos algumas canoas ancoradas e pescadores consertando as velhas 'redes de arrasto', que, em nossas divagações, lembramos de quando aquele recanto bucólico recebia aos domingos e feriados centenas de pessoas que iam se banhar nas águas limpas do Rio Sergipe (MELINS, 2007, p. 320) ou em Mario Cabral, que deixa escapar certo lirismo até quando trata do mundo laboral do bairro, "mais romântico da cidade de Aracaju", apesar de habitado, predominantemente, por "gente pobre": "Pela manhã, longos apitos chamam os operários para o trabalho. $E$ as ruas se enchem de homens e de mulheres a caminho de fábricas enormes. À tarde saem operários, em bandos, uma confusão de cores berrantes compondo uma tela, encharcada de vida e de colorido". (CABRAL, 1955, p. 281).

16 A ideia de "invenção", aqui adotada, inspira-se na contribuição de Tim Ingold (2012), para quem "a palavra em inglês tradition vem de trade - em português troca, que, originalmente, significava track, ou rastro. Segundo esse autor, e apoiado nas assertivas de Boria Sax, "Estudar uma tradição é rastrear uma criatura, como se fôssemos um caçador de volta no tempo". Cada criatura é sua história, sua tradição, de modo que a seguir é realizar um ato de lembrança e de continuidade com os valores do passado. Geralmente, o nome da criatura é sua história condensada, para que, no seu enunciado, a história seja continuada. Mas ela é continuada também nas vocalizações das próprias criaturas (...), é na sua presença visível manifesta e na sua atividade (INGOLD, 2012, p. 22-23). 
muito procurado por políticos antigos e emergentes. A partir desse evento, promovido para a divulgação da programação da festa na capital, tem início a maratona de cerimônias, shows e espetáculos pela cidade, mas também em várias localidades interioranas, cuja dinâmica pode ser acompanhada através da crônica diária.

Na capital, especificamente, os espaços propriamente festivos e mais concorridos dividemse entre o "Arraial do Povo", montado na Praça de Eventos da Orla da Atalaia, e o "Forró Caju", que tem lugar no Mercado Thales Ferraz, na área mais próxima do Centro Histórico e onde se concentram os maiores shows. Paralelamente, por toda a cidade pipocam os arraiais onde empresas, escolas e repartições públicas promovem as confraternizações alternativas. Curioso notar que, apesar do aspecto "pitoresco" e, às vezes caricato, que se empresta a tais ocasiões, o fato é que elas já se encontram inscritas na suposta tradição, como atividade planejada e prevista na sequência dos costumes locais.

O período junino tem recebido a merecida atenção dos cronistas locais, embora os mais antigos ressaltem a importância de São João em detrimento dos demais que com ele formam a trindade dos chamados santos populares ${ }^{17}$. Amando Fontes, por exemplo, no romance Os Corumbas, atesta a presença do festejo em toda a cidade:

Não havia uma rua, nos subúrbios, onde não se dançasse com calor, ao som dos violões e das sanfonas. Às vezes, num rancho mais humilde, um samba foliento, cadenciado ao ronco dos zabumbas e do "boi", atraía verdadeiras multidões. Nos palacetes da cidade, entre brincos e fogos de salão, gritos, vivas, gargalhadas... (FONTES, 1999, p. 120).

Mario Cabral traz uma descrição mais detalhada dessa grande festa popular em Aracaju, em obra publicada pela primeira vez em 1944, portanto, uma década após o relato anterior, embora preserve o mesmo aspecto nostálgico da festa:

\begin{abstract}
A festa de São João, querida, era a festa dos namorados. Quanta poesia, quanto sonho, quanta ilusão naquelas noites frias do Mês de Junho! O dia 23 amanhecia festivo e engalanado. A festa era da cidade inteira, casa por casa, trecho por trecho, bairro por bairro. O que havia, isso sim, era rivalidade, procurando, cada rua, suplantar em beleza e animação a rua visinha. A festa já vinha do dia $15 \mathrm{com}$ as novenas. Noite após noite, em muitas residências, na sala da frente, o altar enfeitado, as velas tremeluzindo, era rezada a novena de São João, com canto e foguetório. Terminada a novena - a rapaziada não perdia tempo - o altar era desfeito, as cadeiras afastadas para que as dansas fossem iniciadas. Uma sanfona, uma batucada, tudo servia para a brincadeira. Um foguete estourava, minuto a minuto, no céu límpido friorento. E as dansas prosseguiam com muito doce de milho e muito licôr de jenipapo. Na véspera de São João o entusiasmo atingia o seu ponto culminante. As ruas amanheciam embandeiradas, pequeninas bandeiras de papel colorido, vêrdes, azuis, amarelas, vermêlhas, constituíam um verdadeiro docél, palpitando e zumbindo ao sabôr da aragem. Cada família, cuidava, desde cedo, em levantar a sua fogueira, maior ou menor, de acordo com as suas pós-
\end{abstract}

17 A expressão "santos populares" é mais comumente utilizada em Portugal, onde a celebração anual de Santo Antônio, São João e São Pedro é também conhecida por Festejos San Joaninos, modalidade que se inscreve na tradição dos velhos folguedos de origem agrária. 
ses, todas, porém, com um bélo "mastro" no centro, quasi sempre um mamoeiro macho, vêrde e garboso. Enquanto os homens organizavam as batucadas, selecionavam os busca-pés, convidavam amigos e conhecidos, as mulheres, na cosinha, preparavam manauês, pamonhas e cangicas. À tarde começavam as dansas ao som das sanfonas e os sambas ao ritmo das batucadas. A cuica gemia sem parar, vózes, em côro, tiravam um estribilho famoso. À noite o espetáculo era realmente feérico. Milhares de fogueiras, enfileiradas, em dupla linha, iluminavam, no seu mar de fogo, todas as ruas e todos os pontos da cidade. À meia-noite, quando, das fogueiras, só restava um montão de brasas, tinham lugar os "batizados" e os "casamentos". Foguêtes, bombas, traques, ronqueiras, enchiam o ar de detonações ensurdecedoras e a noite de chispas de ouro e de luz. Os balões enchiam o céu de estrelas volantes. As batalhas de busca-pés eram terríveis. Dois grupos se enfrentavam em local amplo, provando a coragem de seus componentes e a qualidade de seus fogos. Batalhavam com as roupas molhadas e com luvas de couro, para evitar incêndios e queimaduras. Muitos fabricantes, queimavam, na boca, até o último instante, busca-pés poderosos (CABRAL, 1955, p. 79-80).

Outro registro memorialista acerca da expressividade dos festejos juninos em Aracaju encontra-se no livro Aracaju romântica que vi e vivi: anos 40 e 50, cujo autor, Murilo Melins, derrama-se em extensa saudade dos tempos de infância e juventude:

Naqueles velhos e bons tempos, os festejos juninos começavam, com a retirada de uma grande árvore linheira nas matas do Manoel Preto ou na Floresta da Ibura. À meia-noite do dia 31 de maio, com o espocar de ronqueiras, bombas e foguetes, ao som dos zabumbas, pífanos e tambores das caceteiras, centenas de pessoas assistiam à elevação do mastro que tinha no seu topo um estandarte de São João. O pioneiro dessa solenidade foi o senhor Leopoldino Moura, no ano de 1910. Daí em diante foi sucedido por outros moradores da Rua São João. No primeiro dia de junho, nossa pequena Aracaju dos morros de areia, ruas empiçarradas e dos costumes provincianos acordava sob os estrondos dos bacamartes, bombas, girândolas e roqueiras, vindo de todos os cantos da cidade, anunciando que as festas juninas tinham começado. A partir desse dia, eram celebradas as trezenas em louvor de Santo Antonio. Durante as 13 noites, grupos alegres de rapazes namoradores e garotas casamenteiras, na maior camaradagem e alegria, faziam peregrinação pelas ruas do Santo Antonio até a igreja da Colina. Depois da solenidade religiosa, diversas casas do bairro abriam suas salas para um "bate-coxas", ao som de um sanfoneiro ou de uma radiola.

(...)

No dia 23, véspera de São João, as ruas amanheciam enfeitadas por fileiras de bandeirinhas verdes e vermelhas feitas de papel de seda. Em algumas casas, lanternas de papel japonês eram acesas em suas fachadas. Em frente às portas, eram colocados arcos feitos de palhas de coqueiros, troncos de mamoneiras, bananeiras ou mamoeiros.

Mal a noite úmida chegava, cadeiras eram colocadas às portas, acendia-se a fogueira e os moradores sentados, assistiam às crianças soltarem os inocentes e confiáveis fogos...

Dentro das casas, as mesas estavam repletas de Canjicas, Pamonhas, Bolos de milho, Manauês. Dentre outros quitutes faziam exalar um cheiro apetitoso vindo da cozinha. Bebidas como licores de figo, jabuticaba e jenipapo além dos paratis e Vermutes eram oferecidos aos convidados (MELINS, 2007, p. 105-107, grifo do autor). 
Apesar da menção rápida que o autor faz às treze noites de Santo Antônio, o conjunto do texto volta-se à descrição da festa de São João, enquanto que na narrativa dos dois primeiros cronistas, a expressividade da festa do Santo Antônio que tão é exaltada nos dias atuais, por parte dos seus fiéis mais ferrenhos, é simplesmente anulada.

Diante do exposto, fica a dúvida sobre se as razões desse descompasso na valoração das duas festas tem mais a ver com o acanhamento das procissões de Santo Antônio nos períodos retratados ou a suposta exuberância deve ser vista como "invenção" por parte dos aferrados e coevos devotos, nascidos e criados no bairro em décadas posteriores às narradas pelos memorialistas.

A escritora Marluce Nascimento Menezes, por exemplo, no livro intitulado Meu Santo Antonio do Aracaju, sublinha a prerrogativa do pertencimento ao bairro, quando afirma que "para os seus moradores era quase uma nação pertencer a Santo Antonio" (2008, p. 89, grifo nosso). A sua descrição da festa realça o fulgor de outrora:

No dia 13 de junho minha rua amanhecia em festa. Logo cedo corríamos para a missa a fim de receber os pãezinhos de Santo Antonio. Durante um ano, ele estaria dentro da lata de farinha com a promessa de nunca faltar alimento em nossa casa. Quando voltávamos, a rua inteira começava num alegre alvoroço a lavagem das portas, janelas e calçadas. (...) As moças e os rapazes começavam a esticar os cordões de bandeirinhas coloridas coladas pacientemente durante os dias anteriores. Minha mãe expunha vaidosa, os seus antúrios na calçada, enquanto o resto da vizinhança também exibia palmeiras e elegantes pés de "comigo ninguém pode". (...). Em todos os lares, o almoço, desse dia, era especial em homenagem ao Santo e às visitas que enchiam as casas na alegria do reencontro. Das cozinhas vinham o cheiro bom de canjica, milho verde, pamonha e arroz doce temperado com cravo e canela. As casas que serviam mungunzá colocavam lanternas de papel de seda nas janelas. (...). Do engenho central chegavam minhas primas (...), e com elas, uma dúzia de moças, todas esperançosas devotas de Santo Antonio.

Depois do almoço, as janelas eram abertas de par em par. Toalhas engomadas eram estendidas sobre o peitoril. Em cima, jarros com sorrisos de Maria eram colocados ao centro. Minha rua, perfumada, era um comprido jardim florido. Às cinco horas da tarde, os sinos tocavam e as explosões de foguetes anunciavam que o Santo estava saindo da igrejinha, descendo a colina para visitar o seu povo. Quando a procissão entrava na rua Japaratuba, as pessoas levantavam das cadeiras em referência àquele que era $o$ amparo de todos. Éramos seus filhos e isso tornava a rua uma só família (MENEZES, 2008, p. 115-118, grifo do autor).

Na observação que fizemos da última trezena, pudemos localizar uma série de elementos contidos na crônica de Menezes (2008), a qual nos servirá de roteiro para a apresentação de nossa investigação, tal como essa celebração se estruturou em junho de 2017, mas também, e principalmente, para confrontarmos modelos retóricos na construção de sentido sobre Aracaju. 


\section{A Trezena de Santo Antônio}

A procissão de Santo Antônio aconteceu sempre no dia 13 de junho e, como de costume, reuniu milhares de fiéis, os quais se espalhavam pelo entorno da igreja e pelas ruas próximas onde o cortejo iria passar, provocando grande burburinho no bairro, sempre caracterizado pelo sossego e pela tranquilidade, apesar de o local ser passagem entre a região central da cidade e as áreas de baixa renda de ocupação recente.

Entre os dois eventos limites, apenas sutis alterações são verificadas na estrutura organizacional ao longo das treze noites. Para escapar à regularidade dos cultos verificados nesse meio tempo, destacaremos apenas os aspectos que consideramos essenciais na sustentação das hipóteses aqui levantadas, segundo as quais, a construção acerca do significado e da representação da tradição da festa é bem recente considerando a história do povoado, mas que, ainda assim, funciona como um importante elemento de fortalecimento da ideia de pertencimento na atualidade.

Durante o trezenário, procuramos nos posicionar em pontos diferentes da colina, principalmente no próprio adro da igreja, onde atualmente se realizam as missas campais, em substituição ao espaço interno da igreja, que ficou restrito ao número de fiéis presentes nas celebrações nos últimos anos. Nessa área aberta que também integra a Praça Siqueira Menezes, os devotos se acomodam em cadeiras, tamboretes e bancos trazidos de casa e se distribuem pelos lugares mais estratégicos em função da antecedência com que chegam ao local. Em razão dessa distribuição espacial mais espontânea, não é possível distinguir, claramente, uma hierarquia estabelecida em termos da posição social dos fiéis, embora alguns traços visuais permitam presumir a condição econômica diferenciada. A única divisão visível é o espaço rente ao palanque, reservado às associações religiosas, cujos integrantes auxiliam o padre na liturgia, inclusive na comunhão.

No interior da igreja, porém, verifica-se certa regularidade quando ao perfil sociocultural, já que é o espaço preferido pelos devotos mais idosos ou com alguma dificuldade de locomoção, além de ser o primeiro lugar visitado por aqueles que chegam mais cedo para a trezena, os quais, além das preces iniciais, aproveitam o ensejo para cumprimentar os amigos. No primeiro dia, principalmente, observamos essa confraternização entre amigos e conhecidos de longa data, moradores ou não do bairro, mas que guardam fortes vínculos afetivos com o local.

O próprio Fernando Porto, na obra A cidade do Aracaju (1955/1865), já apontara essa característica conservadora do bairro, disseminada entre os nativos e moradores como a marca identitária do local:

Não possuímos documento algum, descritivo ou cartográfico, capaz de fornecer-nos uma visão detalhada da topografia da região aracajuana nos tempos da mudança. Encontram-se aqui e ali referências vagas a este ou àquele acidente, a este ou àquele topônimo, tudo, porém, na generalidade dos casos, de difícil localização no espaço. Identificação que também é dificultada pelo completo esquecimento em que caíram os 
nomes de outrora, fato que começou a ocorrer pouco depois da mudança. Massarandura, Olaria, Vassouras são nomes completamente estranhos ao aracajuano de hoje. Só o Santo Antonio tem escapado a esta desmemoria coletiva (PORTO, 1991, p. 23, grifo nosso).

Outro espaço de sociabilidade importante verificado durante a festa diz respeito aos fundos da igreja, parte da mesma Praça Siqueira Menezes, normalmente frequentada pelos grupos mais animados e ruidosos, formados, por um lado, pelas crianças que são conduzidas pelos pais, para desfrutar dos poucos brinquedos disponibilizados por ocasião das trezenas e, por outro, por jovens que comparecem ao evento interessados no flerte e nos namoros. Evidentemente, alguns desses jovens integram os movimentos da igreja e participam ativamente das cerimônias religiosas ali encetadas, embora para aqueles que buscam apenas o entretenimento e os contatos entre pares, muitas vezes tais circunstâncias se apresentaram como o preâmbulo de relações mais duradouras e casamentos futuros, conforme pudemos observar, a partir dos testemunhos de casais adultos frequentadores da trezena, os quais reconhecem a vantagem da ocasião e a interseção de Santo Antônio; não necessariamente pela sua fama de casamenteiro, versão que a própria igreja tenta minimizar, embora esse traço não deixe de ser constantemente lembrado, inclusive pelos mais velhos, com um certo tom jocoso e de burla ${ }^{18}$ :

O fato é que devido à presença desses dois grupos, crianças e jovens, a ocasião se apresenta como espaço privilegiado de produção da memória afetiva, melhor formulada no discurso dos adultos que acionam o passado como forma de fortalecimento dessa ideia de pertencimento e motivo dos constantes retornos ao bairro e à festa.

O conjunto dessas características poderia nos iludir acerca do exclusivismo reivindicado pelos devotos mais empedernidos que tratam com Santo Antônio como uma propriedade particular. Contudo, a procissão realizada no último dia, e a quantidade de pessoas presentes nela, dilui rapidamente esses traços diacríticos e obstrui qualquer esforço na busca de padrões. O caráter discreto e reservado dos dias que antecedem a procissão, por ocasião do encerramento da trezena, se transforma naquilo que Goffman chamaria de "reunião concentrada" (GOFFMAN apud GEERTZ, 1978, P. 291), para se referir à participação dispersa e flutuante dessa "entidade sociológica”, que não é suficientemente consistente para chamar de grupo e um tanto quanto desestruturado para chamar multidão, elementos que concorrem para demonstrar a fragilidade da ideia de coesão acionada pelos frequentadores mais assíduos do trezenário.

Nas primeiras movimentações do dia de Santo Antônio, iniciado com a alvorada às 5 horas da manhã e com a realização da primeira missa festiva às 6 horas, até a missa do meio-dia, ainda

18 Trata-se de uma característica do "cristianismo mais humano e mais lírico" que Gilberto Freyre identificou entre nós: "Cristianismo em que o Menino-Deus se identificou com o próprio Cupido e a Virgem Maria e os santos com os interesses de procriação, de geração e de amor mais do que com os de castidade e de ascetismo (...). No culto ao Menino Jesus, à Virgem, aos santos, reponta sempre no cristianismo português a nota idílica e até sensual (...). Impossível conceber-se um cristianismo português ou luso-brasileiro sem essa intimidade entre o devoto e o santo". (FREYRE, 2003, p. 302-303). 
se pode verificar certa reserva e descrição nos gestos e maneiras dos frequentadores, compatível com a suposta tradição. Contudo, a partir do meio-dia e, principalmente após a cerimônia das $15 \mathrm{~h}$, quando a massa de fiéis se avoluma, observa-se uma concentração deles às portas do Convento das Irmãs Terezinha, onde é feita a distribuição dos pães de Santo Antônio, que foram reunidos em grandes quantidades a partir da doação de outros devotos no cumprimento de suas promessas e dívidas com o santo. Porém a quantidade de interessados nesses saquinhos de plástico, contendo às vezes até três unidades de pão, põe de quarentena o "equilíbrio temporário" e acirra uma competição tímida entre os próprios fieis e os organizadores.

Tudo acontece sob o "olhar" complacente e sereno da imagem de Santo Antônio, cujo andor está sendo estruturado e ornamentado pelos seis homens que se alternam nos serviços de marcenaria, eletricidade e decoração no espaço do jardim lateral do convento. Toda a atividade é realizada em clima de descontração e informalidade, atitude que destoa do ar grave dos devotos separados da imagem pelas grades do jardim, que de longe pedem bênçãos ao santo.

A noite a praça é tomada em todos os seus recantos pela massa que se avolumou. Voltada para o palanque, onde se celebra a última missa da trezena, boa parte da multidão não consegue escutar as palavras do Arcebispo, oficiante da noite, inclusive porque o burburinho aumenta quanto mais nos afastamos do epicentro das celebrações. A algazarra das crianças, a zombaria dos mais jovens, a conversação dos adultos e as confabulações dos idosos, todos agora reunidos e formando a mesma massa informe, anuncia a proximidade do ponto alto da festa: a saída do andor.

Os organizadores tentam, em vão, imprimir alguma ordem ao cortejo, permitindo, primeiro, a passagem das autoridades eclesiais e distribuindo, entre os devotos, uma longa corda que, quando suficientemente esticada, criará uma área de proteção para o andor. Essa talvez seja a única divisão verificada durante todo o percurso, entre os de dentro, geralmente homens que se alternam na condução da imagem, e as mulheres que disputam um lugar na corda, de preferência ao lado de Santo Antônio.

O séquito segue desordenadamente por ruas mais escuras e modestas do bairro Cidade Nova, situado na parte posterior da igreja. Alguns, mais animados, seguem apressadamente o trio elétrico que já se antecipou velozmente, enquanto junto ao andor, com sua marcha mais lenta, postam-se os devotos mais fiéis que vão sendo cumprimentados e saudados pelas famílias e grupos de amigos postados nas portas, janelas e varandas de suas casas, onde estiveram pacientemente aguardando a procissão.

Pelo caminho, inúmeros devotos saúdam o andor, pelo qual estiveram esperando na porta de suas casas com seus familiares e amigos. Alguns se contentam com a passagem do cortejo, voltando às suas atividades depois disso, outros engrossam as fileiras do cortejo e completam o longo percurso que inclui, ainda, as avenidas Simeão Sobral e João Ribeiro, sempre presentes no trajeto das antigas procissões. Muitos vão se deixando ficar pelo caminho para retornar as suas casas. No retorno à igreja, antes da subida da ladeira que dá acesso à colina, uma euforia maior toma conta dos participantes que pressentem o fim de mais uma trezena 
Os que alcançam o topo são compensados pela água benta aspergida pelos celebrantes e pela distribuição das rosas, lírios, crisântemos, astromélias e palmas que até então enfeitavam o andor, cuja distribuição provoca mais algazarra entre os fiéis empenhados em apanhar a prenda.

Depois das despedidas de praxe, dos amigos, do santo e da igreja, o largo vai aos poucos se esvaziando, até que só restem os organizadores que cuidarão das últimas providências. Ainda é possível ver os retardatários nas barracas de lanches e suvenirs espalhados na lateral da igreja, garantido a última lembrança. Um misto de alegria e saudade acompanha os fiéis na volta para suas casas. Serve como alívio, talvez para alguns, lembrar que, na sequência, inicia-se o ciclo mais vibrante do ano na cidade e no estado, com seus arraiais juninos.

\section{Considerações Finais}

Quisemos afirmar que a Procissão de Santo Antônio atualiza o princípio social da inversão, observado por DaMatta (1997) na análise do carnaval brasileiro, o "rito sem dono" par excellence, que contrasta com outras cerimônias relacionadas ao mundo das hierarquias, do poder, do comportamento formal e do cumprimento das normas. Em Aracaju, a celebração do santo casamenteiro parece também querer escapar ao modelo dos eventos sociais marcados exclusivamente pela motivação do divino e realizados sob a égide da Igreja (Cf. DAMATTA, 1997, p. 52).

Evidentemente o caráter supostamente "transgressor" da festa de Santo Antônio em Aracaju, notado e anotado acima, talvez não se estenda tanto além dos contornos do controle eclesial como estamos imaginando. Talvez nem seja a cerimônia tão ostensiva quanto um festejo carnavalesco como estivemos afirmando, embora não nos pareça até agora tão descabido acentuar este aspecto zombeteiro dessa devoção local.

Para além dos supostos exageros contidos nesta nossa etnografia, interessa agora, a título de conclusão, destacar o aspecto retórico deste instrumento e estabelecer seus vínculos com as narrativas e produção de sentido que vínhamos explorando nos discursos selecionados. A inscrição etnográfica é uma possibilidade descritiva que busca iluminar a cultura de um lugar e de um tempo precisos, neste caso específico, um documento do presente. Mas ela é também uma invenção. Talvez até uma ficção deliberada como diria Marilyn Strathern (2013); tanto quanto as narrativas de memorialistas, cronistas, poetas e acadêmicos que deixaram escapar em suas produções visões afetivas, mais do que efetivas do passado. As práticas de sentido produzidas por nativos de carne e osso, participantes das cerimônias observadas, somam-se aos discursos acima relacionados, mas não são, por enquanto, objeto desta investigação, devendo seu valor ser reservado para outra ocasião. 


\section{Referências}

AMARAL, Rita de Cássia de Mello Peixoto. Festa à Brasileira. Significados do festejar, no país que "não é sério". 1998. 387 f. Tese (Doutorado em Antropologia) - Faculdade de Filosofia e Ciências Humanas, Universidade de São Paulo, São Paulo. Disponível em: http://www.teses.usp.br/teses/disponiveis/8/8134/tde-21102004-134208/pt-br. php Acesso em: 23 ago. 2009.

ARAÚJO, Hélio Mário et al. (Org.). O ambiente urbano: visões geográficas de Aracaju. São Cristóvão: Editora UFS, 2006.

AVÉ-LALLEMANT, Robert. Excursão à Província de Sergipe. Viajando para Aracaju no Rio Cotinguiba. Maruim.

Revista do Instituto Histórico e Geográfico de Sergipe, Aracaju, v. 21, p. 92-99, 1961.

BARRETO, Luiz Antonio. Pequeno dicionário prático de nomes e denominações de Aracaju. Aracaju: ITBEC/ BANESE, 2002.

BENEDICT, Ruth Benedict. Configurações de Cultura na América do Norte. CASTRO, Celso. Cultura e Personalidade. Margaret Mead; Ruth Benedict; Edward Sapir. Rio de Janeiro: Zahar, 2015.

CABRAL, Mario. Roteiro de Aracaju: guia sentimental da cidade. Aracaju: Regina, 1955.

CHARTIER, Roger. O mundo como representação. Revista Estudos Avançados, São Paulo, v. 5, n. 11, p. 173-191, abr. 1991. Disponível em: <http://www.scielo.br/scielo.php?script=sci_arttext\&pi$\mathrm{d}=$ S0103-40141991000100010\&lng=en\&nrm=iso $>$. Acesso em: 31 jan. 2018. http://dx.doi.org/10.1590/S010340141991000100010.

CORDEIRO, Graça Îndias. Um lugar na cidade: quotidiano, memória e representação no Bairro da Bica. Lisboa: Dom Quixote, 1997.

COSTA, António Firmino da. Sociedade de Bairro: Dinâmicas Sociais da Identidade Cultural. Oeiras: Celta, 2008. CORDEIRO, Graça Índias; COSTA, António Firmino da. Bairros: contexto e intersecção. Antropologia urbana: cultura e sociedade no Brasil e em Portugal. Rio de Janeiro, Jorge Zahar Editor, p. 58-79, 1999.

DEL PRIORE, Mary. Festas e utopias no Brasil Colonial. São Paulo: Brasiliense, 2000.

FONTES, Amando. Os Corumbas. Rio de Janeiro: José Olympio, 1999.

FORTES NETO, José Bonifácio. Evolução da Paisagem Humana da Cidade do Aracaju. Aracaju: Regina, 1955

FREIRE, Gilberto. Casa-grande \& Senzala: formação da família brasileira sob o regime da economia patriarcal. São Paulo: Global. 2003

FRÚGOLI JUNIOR, Heitor. Festas populares em Lisboa: uma etnografia a partir do Bairro Alto. Etnográfica, Lisboa, v. 18, n. 1, p. 77-98, 2014.

GEETZ, Clifford. A Interpretação das culturas. Rio de Janeiro: LTC, 1978.

INGOLD, Tim. Caminhando com dragões: em direção ao lado selvagem. In: STEIL, Carlos Alberto; CARVALHO, Isabel Cristina de Moura (Orgs.). Cultura, percepção e ambiente: diálogos com Tim Ingold. São Paulo: Terceiro Nome, 2012.

DAMATTA, Roberto. Carnavais, malandros e heróis: para uma sociologia do dilema brasileiro. Rio de Janeiro: Rocco, 1997.

. Edmund Ronald Leach: antropologia. São Paulo: Ática, 1983.

LOUREIRO, Kátia Afonso Silva. A trajetória Urbana de Aracaju, em tempo de interferir. Instituto de Economia e Pesquisas, 1983.

MELINS, Murilo. Aracaju Romântica que vi e vivi. Aracaju: Editora Unit, 2007.

MENEZES, Marluce Nascimento. Meu Santo Antonio do Aracaju. Natal: s/ed, 2008.

PORTO, Fernando de Figueiredo. A cidade de Aracaju (1855-1865). Ensaio de evolução urbana. Aracaju: FUN-

DESC, 1991. 
Alguns nomes antigos do Aracaju. Aracaju: Gráfica Editora J. Andrade Ltda., 2003.

RAFAEL, Ulisses N. Festas populares sob perspectiva comparativa: Brasil e Portugal. In: SANDRONI, Carlos; SALLES, Sandro Guimarães de. (Orgs.). Patrimônio cultural em discussão: novos desafios teórico-metodológicos. Recife: Editora Universitária UFPE, 2013. p. 58-84.

Relatorio com que foi aberta a $2^{\mathrm{a}}$ sessão da undecima legislatura da Assembléa Provincial de Sergipe no dia 1.o de fevereiro de 1857 pelo excellentissimo presidente, doutor Salvador Correia de Sá e Benevides. Sergipe: Typ. Provincial, 1857.

Relatorio apresentado à Assembléa Provincial de Sergipe no dia 5 de março de 1860 pelo presidente Manuel da Cunha Galvão. Bahia: Typ. Poggetti de Catellina \& Comp., 1860.

SANTOS NETO, Alexandre Ferreira. As décimas urbanas de Aracaju. Bairro de Santo Antonio e Vila do Socorro (1873-1880). 2005. 106 f. Monografia (Licenciatura em História) - Departamento de História, Universidade Federal de Sergipe, São Cristóvão.

SANTOS, Antonio Flavio Inocêncio dos. Fontes para História das Freguesias de Sergipe no Século XVIII. 2008. 97 f. Monografia (Licenciatura em História) - Departamento de História, Universidade Federal de Sergipe, São Cristóvão.

SANTOS, Waldefranklin Rolim dos. Práticas e apropriações na construção do urbano em Aracaju. 2007. 144 f. Dissertação (Mestrado em Desenvolvimento e Meio Ambiente) - Programa Regional de Pós-Graduação em Desenvolvimento e Meio Ambiente, Universidade Federal de Sergipe, São Cristóvão.

SEBRÃO SOBRINHO. Laudas da História do Aracaju. Aracaju: Prefeitura Municipal, 1955.

SILVA, José Calazans Brandão da. Como nasceu Aracaju. Folha da Manhã. Aracaju, p. 1, 17 mar. 1939.

STRATHERN, Marilyn. Fora de contexto. As ficções persuasivas da antropologia. São Paulo: Terceiro Nome, 2013. VEIGA, Manuel (Ed.). Cabo Verde: insularidade e literatura. KARTHALA Editions, 1998.

VILAR, José Wellington Carvalho. Os espaços diferenciados da cidade de Aracaju: uma proposta de classificação. Revista de Aracaju, Aracaju, n. 9, p. 87-99, 2002.

WEBER, Max. Economia e sociedade: fundamentos da sociologia compreensiva. Brasília: Ed. UnB, 1994.

Recebido em: 07/03/2018

Aceito em: 21/11/2018 